\title{
ENTREVISTA CON JIM SHEDDEN \\ EL APRENDIZAJE NO OCURRIRÁ \\ EN MEDIO DE UNA MALLA \\ CURRICULAR TRADICIONAL
}

Bruce Mau es, sin lugar a dudas, uno de los más influyentes diseñadores contemporáneos. Ya sea mediante sus trabajos editoriales -como su clásica colaboración con Rem Koolhaas en $S, M, L, X L$ o en solitario en el colosal Life Style- o a través de la práctica cotidiana en su oficina de diseño (Bruce Mau Design) con sede en Toronto, Mau $y$ sus colaboradores son un referente ineludible en el mundo de la práctica. Pero el siempre expansivo Mau no ha limitado su trabajo al mundo de la práctica de diseño, incursionando en el mundo de la educación con su proyecto en conjunto con la George Brown-Toronto City College, el Institute without Boundaries. Y como siempre, ha entrado con todo.

El Institute without Boundaries es un híbrido, inclasificable si nos guiamos por las convenciones educacionales imperantes en la actualidad. Mitad curso de postgrado, mitad estudio de diseño, el IwB es organizacionalmente innovador, pero además responde a un propósito superior: ejecutar y ser parte del proyecto Massive Change, largamente desarrollado por Mau.

En esta breve entrevista con Jim Shedden, Vice-presidente de Desarrollo Bruce Mau Design Inc., desde la Revista Chilena de Diseño discutimos con él algunos de los puntos más relevantes del proyecto y de su sentido en el contexto del diseño contemporáneo. 
RCHD: Institute without Boundaries parece ser una de las instituciones de educación en diseño más ideológicas de la actualidad, como lo han sido también o lo son Bauhaus, Cranbrook y otras. ¿̇ Puedes contarnos más acerca cómo el discurso afecta e informa la experiencia de aprendizaje/enseñanza? En otras palabras íes su estilo de enseñanza -basado en la práctica en el mundo real, con proyectos reales - una manifestación del discurso de Bruce Mau?

LA COLA No

ES LA QUE

MENEA AL

PERRO

JS: El proceso de aprendizaje está basado más que nada en la práctica en nuestro estudio. Cuando fuimos consultados por el George Brown College para que propusiésemos un proyecto educacional nos costó mucho hacerlo, pero luego nos dimos cuenta de que el sistema usado en nuestro estudio está basado en el aprendizaje; lo que en nuestra opinión es un modelo educacional muy superior a los modelos tradicionales. No esoy seguro de ir tan lejos como para elevar esto al nivel de un "discurso" porque es sumamente simple: creemos que el aprendizaje se facilita al hacer. Estamos convencidos que el modelo tradicional, de "transmisión", genera resultados mediocres. En el Institute without Boundaries lo siguiente es fundamental:

I. El aprendizaje no ocurrirá en medio de una malla curricular tradicional. En cambio, los estudiantes trabajan en proyectos públicos reales y de gran tamaño, con responsabilidad hacía los clientes. (Como por ejemplo la Galería de Arte de Vancouver, Phaidon, Umbra, etc.)

2. El modelo que hemos usado en este proyecto demanda tanto un espiritu emprendedor como la colaboración. A veces, estos impulsos entran en conflicto entre sí.

3. El pensamiento crítico, la creatividad y la colaboración, son características mucho más importantes que cualquier "habilidad dura". Todos deben aprender las habilidades necesarias para terminar bien un trabajo determinado, pero la cola no es la que menea al perro. 
RCHD: Parece haber una cierta tendencia en todo el mundo, por lo menos en educación de diseño y especialmente en estudios de posgrado, de retomar un acercamiento más directo a la enseñanza, prescindiendo muchas veces de la autoridad del profesor y dejando al estudiante entrar en contacto con el mundo real. ¿Piensas que esta experiencia de aprendizaje es una evolución del estilo más clásico - profesor y el alumno en la sala de clases- , que eventualmente lo reemplazará, - es simplemente una alternativa en un mercado eduacional diversificado?

JS: Por el momento es simplemente una alternativa en el mercado, pero obviamente nosotros creemos que es un modelo superior. Es el modelo de la Misión Apollo y del Proyecto Manhattan.

No es completamente cierto que la autoridad del profesor sea reemplazada. Paradojalmente, cuando tú entregas poder a los estudiantes para que experimenten el trabajo directamente, con todos los riesgos que eso implica, existe una presión aún mayor para encontrar liderazgos fuertes.

El ejemplo que usamos a veces es el del personaje de Jack Black en la pelicula School of Rock. Si has visto el film, entenderás a lo que me refiero. La batalla de las bandas es

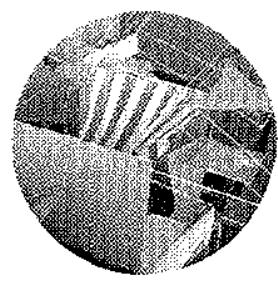
una "Gran Meta"; los estudiantes deben aprender a hacer de todo-incluyendo la colaboración-. Y todos se embarcan en un importante viaje de autotransformación. Si no la has visto, te la recomiendo.

RCHD: ¿Cuál es el objetivo final en el Institute without Boundories? ¿La Implementación del proyecto Massive Change? ¿la creación de una nueva clase de điseñadores?

JS: La creación de un nueva clase de diseñador. Y cambiar el mundo. Eso suena un poco exagerado, pero fuimos inspirados por una frase de Dean Kamen: "Si no va a 
cambiar al mundo, entonces cámbiate a algo que sí lo hará". Existen muchas maneras de cambiar el mundo. Puedes hacerlo de la forma en que la variada involucrada en Massive Change lo ha hecho, o puedes hacerlo simplomente creando instituciones más inteligentes, comu: caciones más efectivas y llevando alegría a la vida

ENTREGAR PODER A LOS ESTUDIANTES de las personas.

Notas:

1 Encontrarán gran cantigad de información soture los distintos proyectos de Bruce Mau en: www. institutewithoutboundaries.com, www.brucemau.com,

www.massivechange.com y www.massivechargeinaction.virtualmuseum.ca
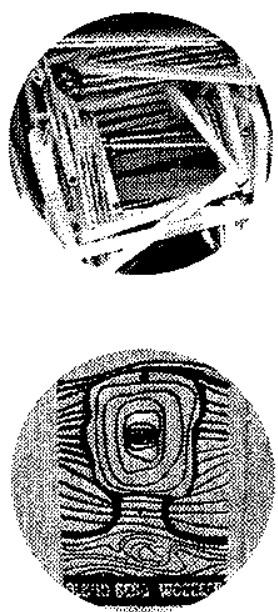